\title{
Dementia Research in the Caribbean Hispanic Islands: Present Findings and Future Trends
}

\author{
Daisy Acosta ${ }^{1 \dagger}$, Jorge J. Llibre-Guerra ${ }^{2,3 * \dagger}$, Ivonne Z. Jiménez-Velázquez ${ }^{4}$ and \\ Juan J. Llibre-Rodríguez ${ }^{1,5}$
}

${ }^{1}$ Department of Internal Medicine, Universidad Nacional Pedro Henriquez Urena, Santo Domingo, Dominican Republic, ${ }^{2}$ Department of Neurology, Washington University School of Medicine in St. Louis, St. Louis, MO, United States, ${ }^{3}$ National Institute of Neurology and Neurosurgery, Habana, Cuba, ${ }^{4}$ Department of Internal Medicine, Medical Sciences Campus, University of Puerto Rico, San Juan, Puerto Rico, ${ }^{5}$ Finlay-Albarrán Medicine Faculty, Universidad de Ciencias Medicas, Habana, Cuba

OPEN ACCESS

Edited by:

Maira Okada de Oliveira, University of São Paulo, Brazil

Reviewed by:

Hongdao Meng

University of South Florida,

United States

Patricia M. Alt,

Towson University, United States

*Correspondence:

Jorge J. Llibre-Guerra jorge.llibre@gbhi.org

tThese authors have contributed equally to this work

Specialty section: This article was submitted to Aging and Public Health, a section of the journal Frontiers in Public Health

Received: 30 September 2020 Accepted: 18 December 2020

Published: 18 January 2021

Citation:

Acosta D, Llibre-Guerra JJ,

Jiménez-Velázquez IZ and Llibre-Rodríguez JJ (2021) Dementia Research in the Caribbean Hispanic Islands: Present Findings and Future

Trends.

Front. Public Health 8:611998. doi: 10.3389/fpubh.2020.611998
During the last decade, the Caribbean Hispanic islands experienced accelerated demographic aging, representing the fastest aging region within Latin America. Age-related non-communicable diseases, including dementia, are now reported at high prevalence. The Caribbean islands share similar genetic ancestry, culture, migration patterns, and risk profiles, providing a unique setting to understand dementia in the Caribbean-Hispanics. This perspective article aimed to describe the impact of dementia in the Caribbean, at a local and regional level and reflect on research strategies to address dementia. We report on 10/66 project findings, described research projects and regional plans for the region. According to our results, the prevalence of dementia in the Caribbean is the highest in Latin America, with $11.7 \%$ in Dominican Republic, $11.6 \%$ in Puerto Rico, and $10.8 \%$ in Cuba. Preliminary data from new waves of the 10/66 study shows increasing numbers of dementia cases. Furthermore, dementia is expected to be one of the most serious medical and social issues confronted by Caribbean health systems. However, there is a scarcity of knowledge, awareness, and health services to deal with this public health crisis. In light of the new evidence, local and regional strategies are underway to better understand dementia trends for the region and develop policies aimed to decrease the impact of dementia. Implementation of our national plans is critical to deal with an aging population with high dementia rates. Current recommendations include emphasizing public health prevention campaigns to address modifiable risk factors and expand support to caregiver and family interventions.

Keywords: dementia, prevalence, incidence, Caribbean hispanics, regional policies

\section{INTRODUCTION}

Epidemiological studies show a rapid increase in dementia in Hispanic populations $(1,2)$. Approximately twelve percent of older adults in the Latino population are diagnosed with Alzheimer's Dementia (AD), representing the highest growing proportion of $\mathrm{AD}$ cases in any ethnic group $(3,4)$. However, there is little to no understanding of disease onset, progression, and biomarker trajectories in Latino populations (5). Furthermore, most of the AD studies tend to include Latinos as a unique group, failing to sufficiently account for the real richness of linguistic, ethnic, ancestry, cultural, and socioeconomic diversity represented across Latino communities. 
In relation to other Latino populations, Caribbean-Hispanics have several differences in customs, traditions, nutritional patterns, risk behaviors, and genetic admixtures, which may differentially impact the prevalence of dementia and expression of its symptoms. Furthermore, during the last decade, the Hispanic Caribbean islands (Cuba, Dominican Republic, and Puerto Rico) experienced accelerated demographic aging, representing the fastest aging region within Latin America, which posed a unique challenge for aging and dementia $(6,7)$. The Caribbean Hispanics represent $57.6 \%$ of the Caribbean population (Cuba $=11,326,616$, Dominican Republic $=10,847,910$, Puerto Rico $=3,193,694)$ region (6).

This perspective article aimed to examine the associations of genetics and socioeconomic determinants with dementia and describe the impact of dementia in the Hispanic Caribbean islands at a local and regional level. In addition, we present current research and describe future projects in the region. Finally, we share current dementia strategies aimed to address this epidemic within the Caribbean area.

\section{AGING AND DEMENTIA IN THE CARIBBEAN HISPANIC}

The Caribbean is undergoing increasingly rapid population aging with the proportion of older persons (60 and over) increasing from $10 \%$ in 2000 to $14 \%$ in 2015 , and projected to reach $25 \%$ by 2050 (6). The rate of demographic aging is substantially faster than occurred in western industrialized societies in the past $(8,9)$. Consequently, compared to High-Income Countries, the Caribbean region must adapt more quickly to aging populations, posing a challenge to more fragile economies and less prepared health care systems. Low fertility rates, a decrease in birth rate, and increased life expectancy due to medical advancements are the main factors related to the Caribbean's aging phenomenon (7). In addition, migration has played a unique role in the aging process within the Caribbean Hispanic region; the three islands have experienced extensive diasporas in the last century, with these large migrations-primarily to the United States (US) establishing such well-known communities as Little Havana in Miami, Hispanic Harlem, and Washington Heights, in New York $(10,11)$. Recently, migration from PR to US increased after Hurricanes Irma and Maria (Sept 2017). Migrants are often young, and their departure has re-shape the population structure, as a result the age structure of the population have change significantly in the Caribbean islands.

As number and proportion of older persons increase, a central question to the Caribbean region is whether the aging of this population will be accompanied by sustained or improved health, better quality of life, and sufficient social and economic resources. To date, the increase in life expectancy has not been coupled with improvements in lifestyle; risk behaviors such as consuming high fat and carbohydrate diets, smoking, and sedentarism are becoming more common. Likewise, population aging has been associated with a sustained increase in non-communicable diseases, including neurodegenerative disorders, like dementia $(2,12)$. Dementia has become one of the most serious medical and social issues confronted by Caribbean health systems, with a markedly elevated prevalence and incidence compared to other Latin American countries in general (2).

Since 2003, the three islands in a coordinated effort led a major epidemiological study (Figure 1) to determine dementia prevalence, incidence, and impact across Caribbean countries using a validated and standard methodology (13). The studies were done under the umbrella of the 10/66 protocols (13), a multinational research initiative aimed to provide a detailed evidence to inform the development and implementation of policies for improving the health and social welfare of older people in low and middle income countries (14). The 10/66 studies encompass new methods to dementia research in Low and Middle Income countries (LMIC) by developing a novel approach to diagnosing dementia (the 10/66 Dementia Diagnosis) and addressing difficulties in making diagnoses among older people with little or no education and the use of standardized protocols across all sites $(13,15)$. Although, the 10/66 study included several Latin America countries, India, and China, in this perspective article we focus on the Hispanic Caribbean studies. Further details of the 10/66 studies have been described elsewhere $(4,16)$.

In the Caribbean region, the $10 / 66$ project surveyed 6833 residents, aged 65 and over, in Cuba $(n=2813)$ and the Dominican Republic $(n=2011)$ from 2003 to 2007, and in Puerto Rico $(n=2009)$ from 2006 to 2008. The interviews were done in a single phase, and the methodology allowed for the diagnosis of dementia and its subtypes, as well as other mental disorders. Data obtained included sociodemographic characteristics, physical health, anthropometric measures; information about risk factors, disability, frailty, utilization of health services, income, lifestyle (including nutrition and exercise), care characteristics, caregiver burden, and genetic risk markers (including ApoE-4); implemented together with a physical and neurological examination. An interview with a reliable informant was required. An incidence phase (second wave) was conducted 3 to 4 years after cohort enrollment, 2007 to 2011. A third wave of the 10/66 protocol is currently underway (details of this new wave are provided below).

The 10/66 studies in the Caribbean (Figure 1) have led to several publications on the prevalence and incidence of dementia and other chronic diseases (hypertension, stroke, anemia, diabetes), the impact of dementia in terms of disability, dependency, economic cost, care arrangements, and access to services (17-20). We have focused our attention on determinants of longitudinal outcomes, specifically incident dementia, mortality, dependence, risk factors, and course of dementia/ and Mild Cognitive Impairment. According to our epidemiological studies, using the same methodology in all three countries, the prevalence of dementia in individuals 65 years old and over is $\sim 11.7 \%$ in DR, $11.6 \%$ in the PR, and $10.8 \%$ in Cuba (Table 1). Preliminary data from a third wave of the $10 / 66$ study suggest and in dementia prevalence relative to previous waves, probably related to a higher frequency of vascular risk factors and poor control of non-communicable diseases, including hypertension, diabetes, etc. With this continuing trend, 


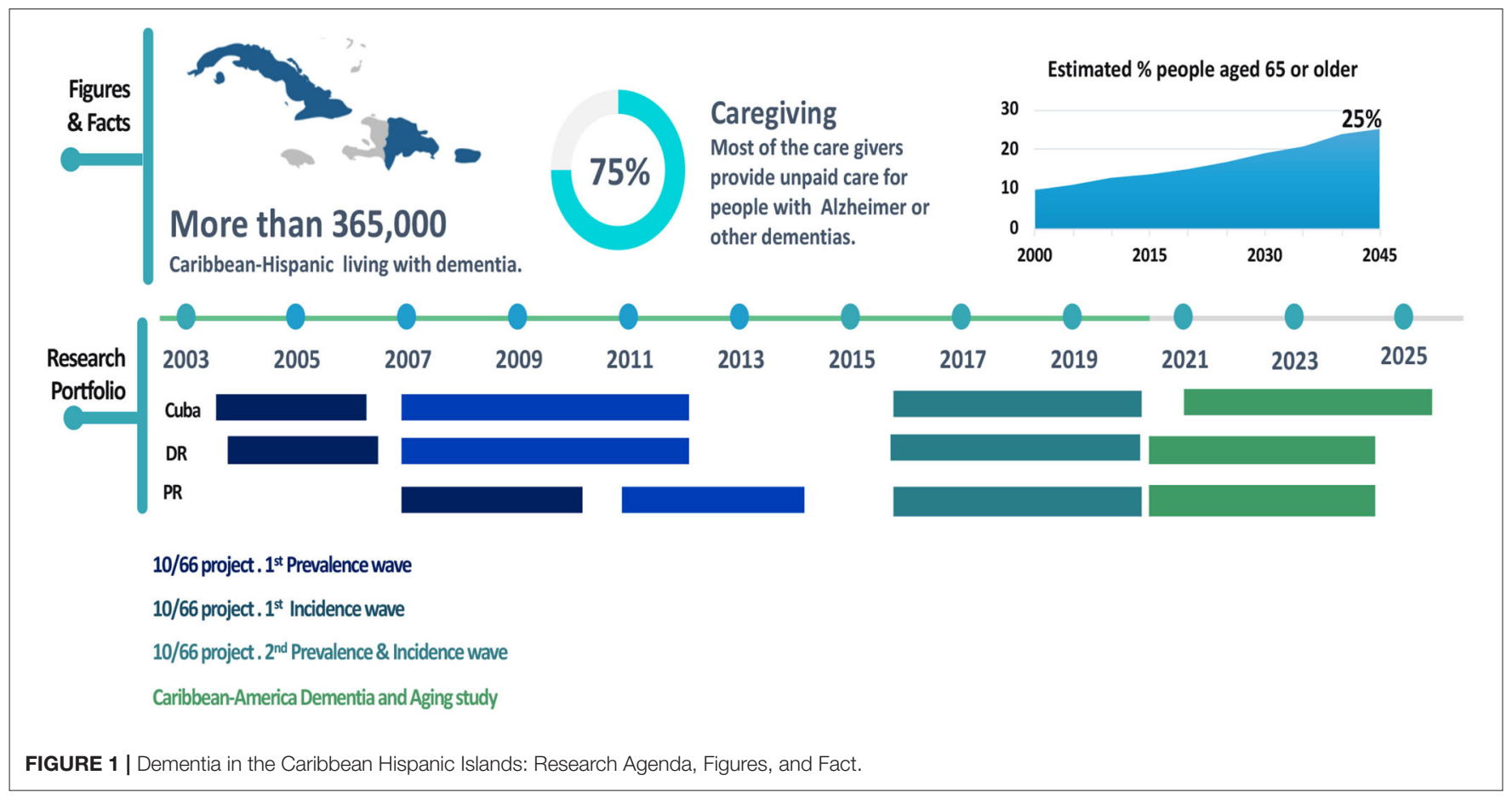

TABLE 1 | Caribbean Hispanics Islands population characteristics and 10/66 cohort profile.

\begin{tabular}{|c|c|c|c|}
\hline & Cuba & $\begin{array}{l}\text { Dominican } \\
\text { Republic }\end{array}$ & Puerto Rico \\
\hline Population Size, (No) millions & 11.1 & 10.6 & 3.2 \\
\hline Over age $65,(\%)$ & 15 & 7 & 15 \\
\hline Life expectancy at birth (years) & 80 & 74 & 80 \\
\hline Fertility rate (birth per woman) & 1.7 & 2.4 & 1.1 \\
\hline \multicolumn{4}{|l|}{ 10/66 baseline characteristics } \\
\hline Participants, No & 2813 & 2011 & 2009 \\
\hline Response Rate (\%) & 94 & 95 & 93 \\
\hline \multicolumn{4}{|l|}{ Age (years), No (\%) } \\
\hline $65-69$ & $715(25.5)$ & $533(26.5)$ & $414(20.6)$ \\
\hline $70-74$ & $747(26.6)$ & 520 (25.9) & $456(22.7)$ \\
\hline $75-79$ & $618(22.0)$ & $396(19.7)$ & $483(24.0)$ \\
\hline$>79$ & $726(25.9)$ & $561(27.9)$ & $656(12.0)$ \\
\hline Gender (F), No (\%) & $1836(65.3)$ & $1325(66)$ & $1347(67.3)$ \\
\hline Dementia, No (\%) & 292 (10.4) & $235(11.7)$ & $233(11.6)$ \\
\hline Mild Cognitive Impairment, No (\%) & $42(1.5)$ & $26(1.3)$ & $68(3.4)$ \\
\hline Stroke, No (\%) & $216(7.7)$ & $175(8.7)$ & $168(8.4)$ \\
\hline Hypertension, No (\%) & 1624 (57.9) & 968 (48.6) & $518(32.1)$ \\
\hline
\end{tabular}

by 2050 , dementia in our countries may have one of the world's highest prevalence (with an estimated increase of 215\%) $(21,22)$.

In the region, the main risk factors for dementia included: older age, family history of dementia, and lower levels of education. Poor cardiovascular health was associated with a higher incidence rate (23). Dementia is also among the top ten causes of death (4th-Puerto Rico, 6th-Cuba, 8th-Dominican Republic) $(23,24)$. However, due to the relative lack of early diagnosis and under registry on death certificates, current reports are likely to be under estimated.

Finally, the total direct and indirect costs of dementia was estimated to be 3.5 billion dollars, which is expected to double in 20 years (22).

As mentioned earlier, a third wave of assessments using an abbreviated form of the primary 10/66 survey is currently underway, $\sim 10$ years after the original baseline surveys (20162020). For the new survey (third wave, $n=6000$ ), we are revisiting the original catchment areas to generate a revised representative estimate of the prevalence of dementia for the residents who are 65 years old or older; the updated sample includes those individuals who, since the first wave of the survey have been incorporated into the age group of interest, either from having aged into it or from having moved into the areas. The new, third-wave prevalence survey includes a comprehensive assessment of health status, which will consist of spirometry, body mass index, visual acuity, grip strength, and tests to determine the presence of hearing impairment (16). The new wave aim to determine the changes in prevalence and incidence of dementia in the region and its associated risk factors-emphasizing cardiovascular issuesand to evaluate probable associations with APOE gene, markers of inflamation and immunusenescence. Moreover, a nested cohort of 300 individuals was randomly selected (150 with a high risk of incident dependence and 150 without) aimed to explore markers of frailty, including extensive laboratory testing of frailty biomarkers. This sub-group will be followed 18 months later to re-assess vital status, needs for care, disability, 
cognitive function, and significant health-related life events in the intervening period.

\section{POPULATION ADMIXTURE, GENETICS, AND CARIBBEAN HISPANICS}

The Caribbean Hispanic population is highly multiethnic, reflecting its complex colonial origins. Intermarriage between diverse groups is widespread, and estimates of the percentage of African descent people vary enormously, ranging from 34 to $62 \%$ (population genetic admixture includes mainly European and African ancestry, with little contribution of Indigenous ancestry) $(25,26)$. This genetic ancestry pattern is different from the one described in South America, which includes predominantly European and Indigenous populations (27). The differences in genetics between the Caribbean-Hispanic and non-Caribbean Hispanics may yield relevant information regarding the influence of admixture background on dementia risk. For example, the risk of $\mathrm{AD}$ associated with the $A P O E-\varepsilon 4$ allele has been found to vary according with African ancestry proportions $(28,29)$.

According to our studies, the association between dementia and $A P O E-\epsilon 4$ is weaker in Caribbean Hispanics compared to Caucasian populations. In the three Caribbean islands being an $A P O E-\epsilon 4$ carrier increases the risk to develop dementia by two folds (SHR 2.03 [1.32-3.11]); in Caucasian populations the risk among $A P O E-\epsilon 4$ carriers is 10 to 15 times higher than in non $A P O E-\epsilon 4$ carriers $(28,30,31)$. To date only $3 \%$ of genetics studies in $\mathrm{AD}$ have been done in Hispanics population; (32, 33) like $A P O E-\epsilon 4$, other genetic variants previously described in Caucasians (e.g., TREM2, SORL1, ABCA7) may have a differential risk among the Hispanic population; therefore the influences of genetic risk factors in Caribbean Hispanics should be explored in future studies.

The frequency of Dominantly Inherited Alzheimer disease (DIAD) is relatively high in the Caribbean countries compare to Europe and US; $(33,34)$ which can be attributable to common ancestors causing a founder effect during early colonization periods $(35,36)$. It is very likely that the establishment of new colonies in the Caribbean islands combined with a high degree of inbreeding among Caribbean populations (37) created a reduced amount of genetic variation within the new population settlements, influencing the spread of these mutations across the islands. In Cuba, Bertoli et al. (38) described a novel Presenilin 1 (PSEN1) pathogenic variant (PSEN1_L174M) affecting several families (280 family members) in the Cuban western provinces. Furthermore, two decades ago, a family study was developed in New York that included multiplex relatives affected with AD in Dominican Republic and Puerto Rico, leading to the discovery of novel PSEN1 pathogenic variant (PSEN1_G206A) (36). Since 2008, a new Early Onset AD study has been conducted in Puerto Rico, leading to the discovery of 91 unrelated families featuring this pathogenic variant. A total of 682 family members have been evaluated and followed in one of the world's biggest cohorts of early-onset families $(37,39)$. Several studies, observational and clinical trials with novel medications are ongoing in Puerto Rico for family members of the PSEN1 families, as well as for sporadic $\mathrm{AD}$ cases.

\section{REGIONAL AND LOCAL POLICIES IN THE CARIBBEAN}

\section{Education and Training in Dementia}

As mentioned early, the prevalence of dementia is high among use Caribbean-Hispanics, yet knowledge, health services, and awareness of the disease are scarce (40). Awareness and early diagnosis are crucial elements to reduce dementia's impact, benefit patients and caregivers, and reduce treatment costs (41). Early detection can prompt evaluation for reversible causes, improve the care of comorbid illnesses, guide the selection of appropriate symptomatic therapies, and identify the needs for social support (41-43).

Unfortunately, cognitive impairment and dementia diagnosis depend mostly on clinical suspicion, and $\sim 50 \%$ of dementia cases are missed in primary care, delaying detection until later in the disease course. Furthermore, awareness about dementia diagnosis and care is not only relevant for health care professionals, but also for the general population, especially among those caring for someone with dementia; and these are unmet needs in LMIC $(44,45)$. Consequently, there is a current need to increase healthcare providers and caregivers' training options.

Several local and regional strategies have been implemented to address these issues. The Alzheimer's Research Center in Cuba has developed a multidisciplinary Master's degree program to improve early diagnosis, treatment, and support of people living with dementia (46). Through this program, trainees will gain the necessary knowledge to advance research on the dementia field and provide better care to dementia patients and their families. Similar strategies are underway in the Dominican Republic and Puerto Rico. For example, the Department of mental health of the Ministry of health in the Dominican Republic for the last 4 years has been training the primary care workforce in the mhGAP intervention guide (47) with the aim that by 2025 , at least $50 \%$ of the estimated number of people with dementia will receive an accurate diagnosis.

Another need is to expand the training of caregivers. The regional Alzheimer Associations have led a caregiver awareness program to improve caretaking abilities and expand caregivers' support. A full training video-series featuring relevant topics regarding caretaking in dementia and advice from health care professionals are available to view and share free of charge. "Conversando con Los Cuidadores"-new series in Spanishincludes eight videos focusing on critical issues related to the work and role of those who provide care for relatives with dementia. Training of caregivers will enhance their management ability and enables them to handle disruptive situations. The Dominican Alzheimer's Association has been developing online and on-site training sessions to support and decrease the burden associated with caretaking. The 10/66 "Helping Caregivers to Care, train-the-trainer" intervention was tested in a randomized control trial in the DR, providing evidence on the relevance of 
caregiver training to decrease the burden associated with care. This intervention continues to be widely used by the Dominican Alzheimer's Association to train caregivers (alz.co.uk/helpingcarers-to-care). The University of Puerto Rico, Geriatric's Education Center, offers specialized courses to train caregivers in different sites, including a special arrangement with the Dominican Republic Embassy in PR, to train Dominican caregivers working in Puerto Rico. Likewise, there are multiple caregiver training programs in private universities on the island.

\section{LOCAL AND REGIONAL PLANS TO ADDRESS DEMENTIA}

In 2015, Cuba and the Alzheimer's Research Center announced the National plan for dementia, and it was adopted as a National dementia strategy by the Cuban Ministry of health in 2016 (23). The main goals of the Cuban national strategy included: 1 -Increase awareness, information, education, and support for families; 2-Risk reduction (e.g., better control of cardiovascular risk factors, reduce physical inactivity, promote healthy diets among others); 3-Timely diagnosis and access to treatment; 4Improve care for dementia patients and their families; 5 -Reduce stigma around dementia; 6-Increase professional development and train families for patient care; 7-Promote basic, clinical and epidemiological research on dementia; 8-Familiarize health teams with laws protecting the rights of older adults and people with cognitive impairment; 9-Assess and improve the quality of health care, social care, and long-term care support and services. Furthermore, Cuba has taken the first steps in implementing the Global action plan on the public health response to dementia 2017-2025.

Similar to Cuba, in 2015, Puerto Rico launched the Alzheimer's disease Action Plan in response to the World Health Organization's (WHO) call to action, by rating $\mathrm{AD}$ and other dementias as a public health priority. The focal areas of the PLAN were divided into seven pillars: (1) Public Policy (2) Public Health Efforts and Epidemiologic Surveillance (3) Home and Community Caregiving Services (4) Education and Training (5) Diagnosis and Treatment, (6) Long Term Care Services, and (7) Long-Term Care Financing. Each area includes specifics goals to be accomplished by 2025 .

Finally, in July 2020, the Dominican Republic's Ministry of Public Health, in close partnership with Asociación Dominicana de Alzheimer, announced a national strategy for dementia with similar action points as Cuba and Puerto Rico. Future efforts in the region are needed to achieve a coordinated response and plan to address the rising number of dementia cases.

\section{UPCOMING RESEARCH EFFORTS}

The Caribbean American Dementia and Aging Study (CADAS) is new research study funded through the National Institute of Health (R01AG064778) aimed to support regional research efforts to expand the previous waves of 10/66 studies to rural populations and facilitate a nationwide dementia estimate (Figure 1). Results from this project will be further compared with databases of Hispanic data collected in mainland USA, including the Health and Retirement Study (HRS) and Harmonized Cognitive Assessment Protocol (HCAP). In addition, in collaboration with the Alzheimer's Association, several countries in the region will launch the LatAm FINGERS, a multi-domain lifestyle intervention (diet and exercise), aimed to improve cognitive function (48). This study will be conducted from 2020 to 2022 and will recruit 1,300 participants from 13 countries in Latin America, including Argentina, Brazil, Bolivia, Chile, Colombia, Costa Rica, Cuba, Dominican Republic, Ecuador, Mexico, Paraguay, Peru, Puerto Rico, and Uruguay; details of LatAm FINGERS has been described elsewhere (48). Both CADAS and LatAm fingers projects show the relevance of international collaboration to push regional and locals research agendas.

To better understand disease pathology and $\mathrm{AD}$ progression in Caribbean-Hispanics, a new Brain Bank is already in place in $\mathrm{DR}$, another one is being organized in PR. Our final goal is to develop a Hispanic Caribbean Coordinating Center for neuropathology sample collection and storage. To maintain a coordinated research program, Caribbean researchers are meeting several times per year, promoting the work's continuity and keeping the international collaborations. More recently, the Ministry of Higher Education Science and Technology of the Dominican Republic awarded the Brain Bank research funding to expand research on AD pathology, with a special focus in Tau patho-physiology. This project is a joint consortium with a local university, "Pontificia Universidad Catolica Madre y Maestra" and Universidad Autonoma de Mexico (UNAM).

\section{CONCLUSION}

Dementia represents a challenge for public health in developing countries with rapid demographic transitions, such as those occurring in the Caribbean. We propose expanding our research efforts to rural areas and explore gene by environment interactions on dementia risk. Emphasis on genetic family studies and admixture and new clinical trials with Hispanic representation, should continue. The development of brain banks and the implementation of biomarker studies are current research priorities. Implementation of our national plans is critical to deal with an aging population with high dementia rates, ideally a true public health-focused approach should aim at social change and emphasize on public-health prevention campaigns directed to addressing modifiable risk factors and developing caregiver and family interventions.

\section{DATA AVAILABILITY STATEMENT}

Publicly available datasets were analyzed in this study. This data can be found here: https://1066.alz.co.uk/.

\section{ETHICS STATEMENT}

The studies involving human participants were reviewed and approved by Universidad Nacional Pedro Henriquez Ureña, 
Universidad de Ciencias Médicas de la Habana, University of Puerto Rico. The patients/participants provided their written informed consent to participate in this study.

\section{AUTHOR CONTRIBUTIONS}

All authors had full access to all the data in the study and take responsibility for the integrity of the data and the accuracy of the data analysis. JL-R, JL-G, IJ-V, and DA: study concept and design. JL-R, IJ-V, and DA: acquisition, analysis, or interpretation of data. JL-G and DA: drafting of the manuscript. All authors critical revision of the manuscript for important intellectual content. JL-G: project administration. JL-R: study supervision.

\section{FUNDING}

This review was supported by grants from the National Institute on Aging of the National Institutes of Health

\section{REFERENCES}

1. Nitrini R, Bottino CMC, Albala C, Custodio Capuñay NS, Ketzoian C, Llibre Rodriguez JJ, et al. Prevalence of dementia in Latin America: a collaborative study of population-based cohorts. Int Psychogeriatrics. (2009) 21:622-30. doi: 10.1017/S1041610209009430

2. Rodriguez JJL, Ferri CP, Acosta D, Guerra M, Huang Y, Jacob KS, et al. Prevalence of dementia in Latin America, India, and China: a population-based cross-sectional survey. Lancet. (2008) 372:464-74. doi: 10.1016/S0140-6736(08)61002-8

3. Rocca WA, Petersen RC, Knopman DS, Hebert LE, Evans DA, Hall KS, et al. Trends in the incidence and prevalence of Alzheimer's disease, dementia, and cognitive impairment in the United States. Alzheimers Dement. (2011) 7:80-93. doi: 10.1016/j.jalz.2010.11.002

4. Prina AM, Mayston R, Wu Y-T, Prince M. A review of the 10/66 dementia research group. Soc Psychiatry Psychiatr Epidemiol. (2018) 2018:110. doi: 10.1007/s00127-018-1626-7

5. González HM, Tarraf W, Schneiderman N, Fornage M, Vásquez PM, Zeng D, et al. Prevalence and correlates of mild cognitive impairment among diverse hispanics/Latinos: study of latinos-Investigation of neurocognitive aging results. Alzheimer's Dement. (2019) 15:1507-15. doi: 10.1016/j.jalz.2019.08.202

6. Quashie NT, Jones F, Gény LR, Abdulkadri A. Population ageing and sustainable development in the Caribbean: where are we 15 years post MIPAA. Int J Ageing Dev Countries. (2018) 2:128-48.

7. Caribbean SC for the $\mathrm{W}$ on $\mathrm{S}$ the SF for $\mathrm{P}$ to $\mathrm{M}$ the $\mathrm{C}$ of $\mathrm{A}$ in LA the, Population C on, Education D of B SS and, The National Academies of Sciences E M. Aging in Latin America and the Caribbean in Global Perspective. (2015).

8. United Nations, Department of Economic and Social Affairs, Population Division. World Population Ageing 2019: Highlights (ST/ESA/SER.A/430). (2019).

9. Kinsella K. Strengthening the Scientific Foundation for Policymaking to Meet the Challenges of Aging in Latin America and the Caribbean: Summary of a Workshop. Washington, DC: The National Academies Press (2015).

10. Moya JC. A continent of immigrants: postcolonial shifts in the Western Hemisphere. Hisp Am Hist Rev. (2006) 86:1-28. doi: 10.1215/00182168-86-1-1

11. Rumbaut RG. The making of a people. In: M. Tienda, F. Mitchell, editors. Hispanics and the Future of America. National Academies Press (2006). p. 16-65. Available online at: https://ssrn.com/abstract=1877405.

12. Molero AE, Pino-Ramírez G, Maestre GE. High prevalence of dementia in a caribbean population. Neuroepidemiology. (2007) 29:107-12. doi: $10.1159 / 000109824$ under Award Number R01AG064778, the Alzheimer's Association (SG-20-690363), Ministry of Higher Education Science and Technology (2018-2019-2A3-208) and the World Federation of Neurology (Grants-Aid program). The 10/66 Dementia Research Group's research has been funded by the Welcome Trust Health Consequences of Population Change program (GR066133 - Prevalence phase in Cuba and Brazil; GR080002 - Incidence phase in Peru, Mexico, Argentina, Cuba, Dominican Republic, Venezuela, and China). The content is solely the responsibility of the authors and does not represent the official views of the NIA, AA, MESCYT, WFN or WT.

\section{ACKNOWLEDGMENTS}

We acknowledge the participants' altruism and their families and to the 10/66 research group for their contributions to this study.
13. Prince MJ, De Rodriguez JL, Noriega L, Lopez A, Acosta D, Albanese E, et al. The 10/66 dementia research group's fully operationalised DSMIV dementia computerized diagnostic algorithm, compared with the 10/66 dementia algorithm and a clinician diagnosis: a population validation study. BMC Public Health. (2008) 8:219. doi: 10.1186/1471-2458-8-219

14. Prince MJ. The $10 / 66$ dementia research group - 10 years on. Indian J Psychiatry. (2009) 51(Suppl 1):S8-S15.

15. Prince M, Ferri CP, Acosta D, Albanese E, Arizaga R, Dewey M, et al. The protocols for the 10/66 dementia research group population-based research programme. BMC Public Health. (2007) 7:165. doi: 10.1186/1471-2458-7-165

16. Prina AM, Acosta D, Acostas I, Guerra M, Huang Y, Jotheeswaran AT, et al. Cohort profile: the 10/66 study. Int J Epidemiol. (2016) 46:dyw056. doi: 10.1093/ije/dyw056

17. Sousa RM, Ferri CP, Acosta D, Guerra M, Huang Y, Jacob K, et al. The contribution of chronic diseases to the prevalence of dependence among older people in latin america, china and india: a 10/66 dementia research group population-based survey. BMC Geriatr. (2010) 10:53. doi: 10.1186/1471-2318-10-53

18. Llibre JDJ, López AM, Valhuerdi A, Guerra M, Llibre-Guerra JJ, Sánchez YY, et al. Frailty, dependency and mortality predictors in a cohort of Cuban older adults, 2003-2011. MEDICC Rev. (2014) 16:24-30. doi: 10.37757/MR2014.V16.N1.6

19. Prince M, Acosta D, Ferri CP, Guerra M, Huang Y, Rodriguez JJL, et al. Dementia incidence and mortality in middle-income countries, and associations with indicators of cognitive reserve: a 10/66 dementia research group population-based cohort study. Lancet. (2012) 380:50-8. doi: 10.1016/S0140-6736(12)60399-7

20. Pasquini L, Llibre Guerra J, Prince M, Chua K-C, Prina AM. Neurological signs as early determinants of dementia and predictors of mortality among older adults in Latin America: a 10/66 study using the NEUROEX assessment. BMC Neurol. (2018) 18:163. doi: 10.1186/s12883-0181167-4

21. Coste EL, Prevalencia LA, Alzheimer D, Demencia DE. Informe ADI/Bupa. La Demencia en América: el Coste y la Prevalencia del Alzheimer y Otros Tipos de Demencia. (2013).

22. Prince M, Wimo A, Guerchet M, Gemma-Claire A, Wu Y-T, et al. World Alzheimer Report 2015: The Global Impact of Dementia - An Analysis of Prevalence, Incidence, Cost and Trends. London: Alzheimer's Disease International (2015). p. 84. Available online at: http://www. worldalzreport2015.org/

23. Llibre-Rodríguez, J. de J., Valhuerdi-Cepero A, López-Medina AM, NoriegaFernández L, Porto-Álvarez R, Guerra-HernóndezMA, et al. Cuba's 
aging and Alzheimer longitudinal study. MEDICC Rev. (2017) 19:31-5. doi: 10.37757/MR2017.V19.N1.6

24. Figueroa R, Steenland K, MacNeil JR, Levey AI, Vega IE. Geographical differences in the occurrence of Alzheimer's disease mortality: United States versus puerto rico. Am J Alzheimers Dis Other Demen. (2008) 23:462-9. doi: $10.1177 / 1533317508321909$

25. Moreno-Estrada A, Gravel S, Zakharia F, McCauley JL, Byrnes JK, Gignoux CR, et al. Reconstructing the population genetic history of the caribbean. PLoS Genet. (2013) 9:e1003925. doi: 10.1371/journal.pgen.1003925

26. Homburger JR, Moreno-Estrada A, Gignoux CR, Nelson D, Sanchez E, Ortiz-Tello P, et al. Genomic insights into the ancestry and demographic history of South America. PLoS Genet. (2015) 11:e1005602. doi: 10.1371/journal.pgen.1005602

27. Mao X, Bigham AW, Mei R, Gutierrez G, Weiss KM, Brutsaert TD, et al. A genomewide admixture mapping panel for hispanic/Latino populations. Am J Hum Genet. (2007) 80:1171-8. doi: 10.1086/518564

28. Teruel BM, Rodríguez JJL, McKeigue P, Mesa T TC, Fuentes E, Cepero A $\mathrm{AV}$, et al. Interactions between genetic admixture, ethnic identity, APOE genotype and dementia prevalence in an admixed cuban sample; a crosssectional population survey and nested case-control study. BMC Med Genet. (2011) 12:43. doi: 10.1186/1471-2350-12-43

29. Rajabli F, Feliciano BE, Celis K, Hamilton-Nelson KL, Whitehead PL, Adams $\mathrm{LD}$, et al. Ancestral origin of apoE $\varepsilon 4$ Alzheimer disease risk in puerto rican and african american populations. PLoS Genet. (2018) 14:e1007791. doi: 10.1371/journal.pgen.1007791

30. Blue EE, Horimoto ARVR, Mukherjee S, Wijsman EM, Thornton TA. Local ancestry at aPOE modifies alzheimer's disease risk in Caribbean hispanics. Alzheimers Dement. (2019) 15:1524-32. doi: 10.1016/j.jalz.2019.07.016

31. Cruchaga C, Del-Aguila JL, Saef B, Black K, Fernandez MV, Budde J, et al. Polygenic risk score of sporadic late-onset Alzheimer's disease reveals a shared architecture with the familial and early-onset forms. Alzheimer's Dement. (2018) 14:205-14. doi: 10.1016/j.jalz.2017.08.013

32. Kunkle BW, Grenier-Boley B, Sims R, Bis JC, Damotte V, Naj AC, et al. Genetic meta-analysis of diagnosed Alzheimer's disease identifies new risk loci and implicates a, tau, immunity and lipid processing. Nat Genet. (2019) 51:414-30. doi: 10.1038/s41588-019-0358-2

33. Llibre-Guerra JJ, Li Y, Allegri RF, Mendez PC, Surace EI, Llibre-Rodriguez $\mathrm{JJ}$, et al. Dominantly inherited Alzheimer's disease in Latin America: genetic heterogeneity and clinical phenotypes. Alzheimer's Dement. (2020) 2020:alz.12227. doi: 10.1002/alz.044794

34. Cruts M, Van Duijn CM, Backhovens H, Van Den Broeck M, Wehnert A, Serneels S, et al. Estimation of the genetic contribution of presenilin-1 and-2 mutations in a population-based study of presenile alzheimer disease. Hum Mol Genet. (1998) 7:43-51. doi: 10.1093/hmg/7.1.43

35. DeGiorgio M, Jakobsson M, Rosenberg NA. Explaining worldwide patterns of human genetic variation using a coalescent-based serial founder model of migration outward from Africa. Proc Natl Acad Sci USA. (2009) 106:16057-62. doi: $10.1073 /$ pnas.0903341106

36. Athan ES, Williamson J, Ciappa A, Santana V, Romas SN, Lee JH, et al. A founder mutation in presenilin 1 causing early-onset Alzheimer disease in unrelated Caribbean hispanic families. J Am Med Assoc. (2001) 286:2257-63. doi: 10.1001/jama.286.18.2257
37. Vardarajan BN, Schaid DJ, Reitz C, Lantigua R, Medrano M, JiménezVelázquez IZ, et al. Inbreeding among Caribbean hispanics from the dominican republic and its effects on risk of Alzheimer disease. Genet Med. (2015) 17:639-43. doi: 10.1038/gim.2014.161

38. Bertoli Avella AM, Marcheco Teruel B, Llibre Rodriguez JJ, Gomez Viera N, Borrajero Martinez I, Severijnen EA, et al. A novel presenilin 1 mutation $(\mathrm{L} 174 \mathrm{~m})$ in a large cuban family with early onset Alzheimer disease. Neurogenetics. (2002) 4:97-104. doi: 10.1007/s10048-002-0136-6

39. Lee JH, Cheng R, Vardarajan B, Lantigua R, Reyes-Dumeyer D, Ortmann W, et al. Genetic modifiers of age at onset in carriers of the g206A mutation in pSEN1 with familial Alzheimer disease among Caribbean hispanics. JAMA Neurol. (2015) 72:1043-51. doi: 10.1001/jamaneurol.2015.1424

40. Prince M, Bryce R, Albanese E, Wimo A, Ribeiro W, Ferri CP. The global prevalence of dementia: a systematic review and metaanalysis. Alzheimers Dement. (2013) 9:63-75.e2. doi: 10.1016/j.jalz.2012.11.007

41. Langa KM, Levine DA. The diagnosis and management of mild cognitive impairment: a clinical review. JAMA. (2014) 312:2551-61. doi: 10.1001/jama.2014.13806

42. Robinson L, Tang E, Taylor JP. Dementia: timely diagnosis and early intervention. BMJ. (2015) 350:3029. doi: 10.1136/bmj.h3029

43. Ashford JW, Borson S, O'Hara R, Dash P, Frank L, Robert P, et al. Should older adults be screened for dementia? It is important to screen for evidence of dementia! Alzheimer's Dement. (2007) 3:75-80. doi: 10.1016/j.jalz.2007.03.005

44. Parra MA, Baez S, Allegri R, Nitrini R, Lopera F, Slachevsky A, et al. Dementia in Latin America assessing the present and envisioning the future. Neurology. (2018) 90:222-31. doi: 10.1212/WNL.0000000000004897

45. Gonzalez FJ, Gaona C, Quintero M, Chavez CA, Selga J, Maestre GE. Building capacity for dementia care in Latin America and the Caribbean. Dement Neuropsychol. (2014) 8:310-6. doi: 10.1590/S1980-57642014DN84000002

46. Ms RIB, Drsc JJLMPH, Ms AF. Cuba's strategy for Alzheimer disease and dementia syndromes. MEDICC Rev. (2016) 2016:9-13. doi: 10.37757/MR2016.V18.N4.2

47. Keynejad RC, Dua T, Barbui C, Thornicroft G. WHO mental health gap action programme (mhGAP) intervention guide: a systematic review of evidence from low and middleincome countries. Evid Based Ment Health. (2018) 21:29-33. doi: 10.1136/eb-2017-102750

48. Kivipelto M, Mangialasche F, Snyder HM, Allegri R, Andrieu S, Arai H, et al. World-wide FINGERS network: a global approach to risk reduction and prevention of dementia. Alzheimer's Dement. (2020) 16:1078-94. doi: $10.1002 /$ alz.12123

Conflict of Interest: The authors declare that the research was conducted in the absence of any commercial or financial relationships that could be construed as a potential conflict of interest.

Copyright (C) 2021 Acosta, Llibre-Guerra, Jiménez-Velázquez and Llibre-Rodríguez. This is an open-access article distributed under the terms of the Creative Commons Attribution License (CC BY). The use, distribution or reproduction in other forums is permitted, provided the original author(s) and the copyright owner(s) are credited and that the original publication in this journal is cited, in accordance with accepted academic practice. No use, distribution or reproduction is permitted which does not comply with these terms. 